according to his scheme. This is coupled with the casual assumption that the Kyoto deal can be completely rewritten. Victor vastly underestimates Kyoto's achievement in obtaining agreement and the centrality of the strong US target in return for extensive flexibilities. Indeed, despite its analytical depth, the book is marred - and perhaps the negativity explained - by viewing everything through a US lens. This results in scepticism about US implementation and cynicism about the rest of the world. For example, it is grossly misleading to assert that "no major government has a viable plan for compliance". Ten years in advance of the Kyoto target period (2008-12), the United Kingdom is on track, and, like many other European governments, if its current plans prove inadequate, they will be strengthened and/or supplemented by using Kyoto's mechanisms to achieve compliance.

There are other peculiar inconsistencies. At the core of his attack on emissions trading is the assertion that negotiating allocations is the equivalent of agreeing on how to distribute money, and is hence impossible, or too weak. Yet Kyoto did reach agreement Victor's claim that all this was an accident born of governmental ignorance is arrogant and does not hold water. And his complaint about Kyoto is that the targets are too strong. Indeed, in the United Nations, the European Union, and even in individual governments, negotiations regularly distribute budgets. All that is needed is the common understanding that there is a collective interest in agreeing, and that simply printing more money only leads to inflation.Victor has not factored in the politics of pressure in the hothouse of negotiating allocations. It is the achievement of having agreed in Kyoto that Victor wants to unravel.

Ultimately, Victor's book reminds me of Tolkien's Lord Denethor in The Lord of the Rings, who was given a crystal ball to see events around the world - but only negative ones. Overwhelmed with despair, he led his family to the pyre, decrying the ignorant fools who fought on. He burnt to death just as his allies were mustering for their final victory. David Victor's analysis is that of a fine mind overwhelmed by the problems he sees and led to a destructive conclusion.

Nevertheless, the book should be read by all policy-makers attempting to find international solutions to the climate problem. It identifies the important questions to be answered, and the big problems to be solved. There are answers, and ironically, some may be easier to find while the present US administration is withdrawn from the Kyoto negotiations. Do not follow Victor onto the pyre.

Michael Grubb is at Imperial College, London SW7 $2 B P, U K$. He is author of The Kyoto Protocol: A Guide and Assessment (RIIA/Earthscan,

London; Brookings, Washington).

\section{Knowing the value of nature}

\section{Wild Solutions: How Biodiversity is Money in the Bank}

by Andrew Beattie \& Paul R. Ehrlich

Yale University Press: 2001. 272 pp. \$25.95

\section{E. J. Milner-Gulland}

Every textbook on conservation contains a section where the authors attempt to justify why policy-makers should make the conservation of biodiversity a priority. Although people tend to become conservationists for reasons more to do with the heart than the head, those wishing to make a strong case for conservation tend to downplay arguments based on ethics, aesthetics or spiritual needs, and concentrate on the utilitarian reasons for conservation. It is argued that only if biodiversity is seen to be paying its way, preferably in the short term, will funding for its conservation be forthcoming.

Wild Solutions argues for the conservation of natural resources from a firmly utilitarian perspective. Taking examples from a wide range of taxonomic groups, Andrew Beattie and Paul Ehrlich demonstrate how often-overlooked species are fundamental to our continuing viability. There are many fascinating examples of useful species, such as the glue-squirting velvet worm and the antibiotic-producing Australian bull ant. The authors cover a range of topics, including decomposition, medicines, problems in construction and motion, water and nutrient cycles, and bioindicators.

Using the concept of the 'natural internet', they describe how the natural world is composed of connections, unknown to most people, which are allowing us to dispose of

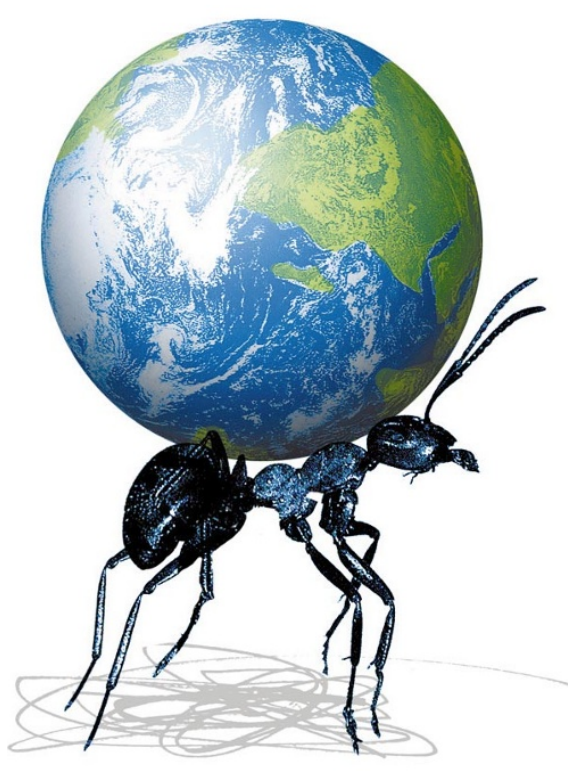

ผ ๑ 2001 Macmillan Magazines Ltd our waste, clean our air and water supplies and pollinate our crop plants. Along the way, the authors also provide powerful ammunition for those who argue that taxonomic studies are crucial to our future well-being. They show how little is known about the planet's biodiversity, and give examples of obscure creatures, stumbled upon by chance, which were subsequently found to be useful to humanity.

The book is almost unrelentingly positive, and an easy read, generating a momentum of energy and excitement about the potential of the natural world to solve many of the problems that face us. By finding where a problem that we face occurs in the natural world, they argue, we are likely to find solutions, either as blueprints for technology or in the form of inspiration. For example, termite air-conditioning has been used as the inspiration for naturally cooled office blocks.

Generally, though, the examples given are discussed briefly, and in little depth - this is an inspirational book for the general reader rather than the scientist. But the chapter on biological control does touch on the complexities involved in exploiting 'wild solutions' to our problems. It explains how introducing new species to solve one problem can create another - the cane toad, water hyacinth and Salvinia are among the examples given.

Reading the book from a UK perspective, however, I was concerned at the absence of any exploration of the issues surrounding the genetic modification of organisms. These are complex issues, hard to discuss in a book of this type. Nevertheless, the target audience in the United Kingdom must be convinced of the benefits of gene technology before it will accept the authors' premise that a combination of sophisticated biotechnology and naturally produced chemicals is a good way to proceed.

The rise of ecological economics as a discipline has made many conservationists believe that, in order to put their case across, they must value biodiversity monetarily. This confuses utilitarian value with monetary value. Beattie and Ehrlich do not attempt this, which I find enormously refreshing. In fact, a strong implicit message in the book is how complex and poorly understood are the mechanisms behind ecological processes, and how meaningless it would be to attempt a full monetary valuation of them.

Some impressive examples of the monetary value of natural services are cited, however. One is the Catskill Mountains, the source of New York city's water supply. The increasing load of pesticides, fertilizers and sewage had threatened to overwhelm the natural water-purification services provided by the Catskills. The costs of constructing a water treatment plant were 
estimated at $\$ 6-8$ billion, with annual operating costs of $\$ 300$ million. By comparison, reducing the pressures on the ecosystem, allowing it once more to provide high-quality water, was estimated to cost $\$ 1.5$ billion. And this was the course of action chosen.

But as the authors say, “... our most important capital is natural capital: biodiversity ... this is the capital of the real world. The currencies based on financial capital derive from the life-support systems and products generated by biodiversity. We know full well that humanity has chosen to operate in a world of financial capital. The way to proceed, therefore, is first to recognize the true worth of the two kinds of capital and then to organize the human economy to preserve both. The value of financial capital is accepted by most people; the value of natural capital is only starting to be recognized."

This book has a limited remit: to demonstrate to the lay reader that the natural world is already supporting our species in ways unknown to many of us, and that many other useful products and services await discovery if we look for them in the right way. The destruction of biodiversity is damaging the life-support systems on which we depend, and cutting off our options for the future. By using a huge range of examples, Beattie and Ehrlich get the point across very effectively.

E. J. Milner-Gulland is at the T. H. Huxley School of Environment, Earth Science and Engineering, Imperial College London, London SW7 2BP, UK.

\section{Murder most putrid}

\section{Maggots, Murder and Men: Memories and Reflections of a Forensic Entomologist}

by Z. Erzinçlioğlu

Harley Books: 2000. 256 pp. £13.95

\section{Mark Benecke}

Here is that rare thing, a good popular book on forensic entomology that is also an illuminating read on forensic science itself and on the art of being an expert witness. Zakaria Erzinçlioğlu (a.k.a. Dr Zak), a forensic entomologist for more than 20 years, covers not only the wonderful world of insects as a tool in forensic investigations, but also the Tertiary geological period, O'nyong-nyong disease, Napoleon Bonaparte, human behaviour, maggot therapy and Sherlock Holmes.

Starting from the statement that "a dead human body is a magnificent and highly nutritious resource", mostly for invertebrates, Erzinçlioğlu sets off on a fascinating trail that takes in both forensic entomology and the nature of forensic evidence. The insect evidence in two of his cases perfectly illustrates the fact that, although much can be ignored at a crime scene, it is important not to overlook vital evidence, or even its absence. In one case, the presence of winter gnats at the crime scene was a plain indication that the victim had died in winter. In another case, however, the presence of minute black scav-

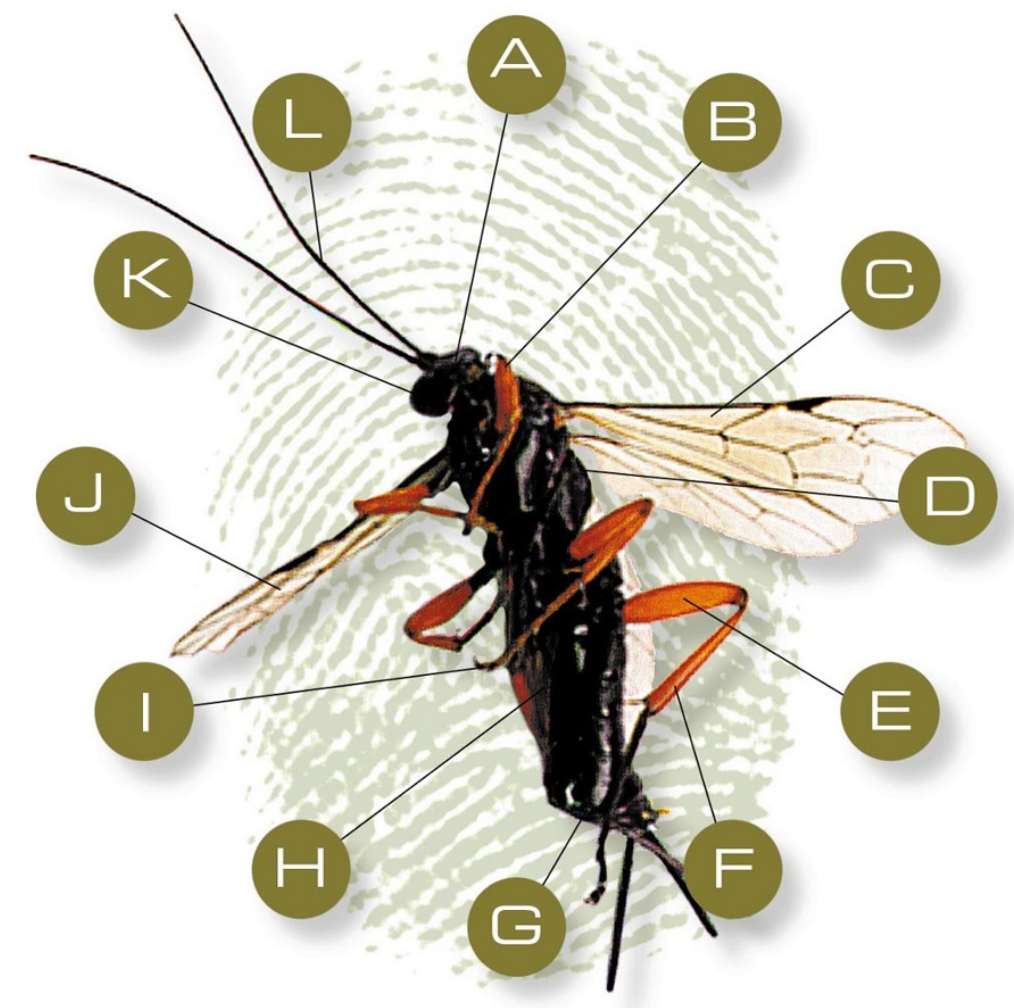

enger flies (which start to breed earlier in the year than other flies) could not be interpreted correctly without recognizing the absence of blowfly maggots. If death had occurred in summer, blowfly maggots would have outcompeted the tiny scavenger flies. The victim must therefore have died in the spring, when blowflies are not active.

In contrast to the everyday work of most natural scientists, forensic scientists, especially the few who work at crime scenes, have to accept that controlled experimental conditions must frequently remain a dream. The complexity of influences in real-life situations can only be simulated by a large number of laboratory experiments, for which there may be no time. To highlight this problem, Erzinçlioğlu discusses the scientific method itself. Because physical evidence from a crime scene can often only be interpreted, instead of delivering an obvious absolute truth, Erzinçlioğlu warns against the danger of going too far. To avoid this trap, a forensic expert not only needs experience but must also have a clear idea of which questions can be answered by a particular investigative method and which cannot.

Case-work can be thrilling, but is also a personal challenge. As Erzinçlioğlu authentically describes, one has "to visit the seediest of dwellings at the most unsocial of hours", carry out "post-mortem examinations late at night" and be "ferociously cross-examined by hostile barristers in court". He shares with the reader the mind-broadening knowledge he has gathered from working in such conditions, and which is the forensic scientist's reward.

Only a mixture of deep specialist knowledge (in Erzinçlioğlu's case, the biology and anatomy of flies and their maggots), lots of enthusiasm and curiosity, up-to-date knowledge of neighbouring disciplines and a touch of singularity can make a scientist into a 'real forensic', and Erzinçlioğlu is a prime example. In his discussions of the nature of justice he has already ruffled some feathers, for he points clearly to unpleasant and often neglected aspects of the justice system, such as incompetent defence consultants who muddy the waters and the fact that forensics in Britain apparently now has to operate according to 'free market' rules.

The energy and efforts of scientists such as Erzinçlioğlu have put forensic entomology back into routine use - as long as a forensic entomologist is available. A special issue of Forensic Science International on forensic entomology is due later this year. So buy this book and enjoy the author's witty, wise and comprehensive thoughts on forensic entomology and forensics in general. Also, try not to steal the lovely black-and-white drawings by Michael Roberts as slides for your future forensic presentations - if you can.

Mark Benecke is Director of International Forensic Research \& Consulting, Postfach 250411, 50520 Cologne, Germany. 